\title{
Normal-to-Coast Transfer of Coarse Suspension in a Surf Area: Modeling and Assessments Based on the Measurements by the Instrumental Complex "Donnaya Stantsiya"
}

\author{
V. Z. Dykman*, O. I. Efremov, M. S. Volikov \\ Marine Hydrophysical Institute, Russian Academy of Sciences, Sevastopol, Russian Federation \\ *e-mail: zaharovich_41@mail.ru
}

\begin{abstract}
The present paper represents the conceptual model of normal-to-coast transfer of the coarse suspension for the waves of frontal direction. The given model is developed based on the data obtained applying by the measurement complex "Donnaya stantsiya" during the expedition in late August - early September 2010 during washing out of the Bakal spit narrow part. Anisotropy of the current velocity wave component results in dependence of integral transfer of the coarse near-bottom suspension upon the period of waves. In the surf area, when these periods exceed the critical value $2.6 \mathrm{~s}$ the suspension washing out is observed; if the periods are shorter accumulation takes place. The west wind velocity corresponding to the critical period makes $4.7 \mathrm{~m} / \mathrm{s}$. Under such a wind, there is no total normal-to-coast transfer of the coarse suspension. The variant of the model developed is proposed to be applied to the situation on Tuzla Island, as there is a certain similarity of the dramatic events on the Bakal Spit and Tuzla Spit in the Kerch Strait. As is known, before 1925 it existed as a single whole with the Taman Peninsula. So, the considered phenomenon is of great importance in connection with the construction of a bridge across the Kerch Strait on the basis the Tuzla Island.
\end{abstract}

Keywords: measurement complex "Donnaya Stantsiya", surf area, near-bottom turbulence, coast washing out.

DOI: 10.22449/1573-160X-2017-4-66-78

(C) 2017, V. Z. Dykman, O. I. Efremov, M. S. Volikov

(C) 2017, Physical Oceanography

Introduction. Wind waves are the main source of energy supply to the coastal area. Ultimately, all the energy accumulated by waves under the wind effect in the open sea dissipates in the coastal zone. In the shallow water a fast transformation of the wave trains coming from deep water occurs. As a result, motions of other types and scales, including near-bottom turbulence and coastal currents are excited. The most marked consequences of the destruction of waves in the coastal zone are the spreading and transfer of bottom sediments, the accumulation of sediments and erosion of the shores.

The study of the regularities in the sand sediment transport under the effect of waves is mainly based on the construction of various physical models of this phenomenon. In hydrodynamic models of fluid flows containing suspended solids, the suspended matter is usually represented as a solid object, characterized by the mean in the granulometric composition concentration and precipitation rate parameters $[1,2]$. In a number of works the suspended matter is considered as a set of discrete particles with certain geometric dimensions $[3,4]$.

A kinetic model of the transport of mineral particles has been developed in Marine Hydrophysical Institute (MHI) of the Russian Academy of Sciences. The distribution functions of suspended particles in this model are closely related to the characteristics of near-bottom turbulence [5].

During sedimentation in turbulent flows the suspended matter particles due to their own inertia acquire a non-oscillating mean acceleration component $\alpha_{\mathrm{p}}$ di- 
rected against gravity. In a subsurface layer of such a kind, the pulsational deceleration of suspended particles is a small amount of the reduced acceleration of gravity $g_{p}$, and directly at the very bottom it can increase by more than an order due to the high frequency of turbulent velocity fluctuations in this area. A kinetic model of the transport of mineral particles is based on the probability distribution function $\varphi(W)$ of suspended solids according to median fall diameter $W$ (settling velocity in non-moving water), $\varphi(W)=\frac{2^{2-q} \sqrt{\pi} q}{\Gamma(q+0,5) \sigma^{2 q}}\left[\frac{1}{2}-\Phi_{0}(W / \sigma)\right] W^{2 q-1}$. Here, the dispersion of the turbulent velocity fluctuations determines the position of the of the sharp decrease area in the distribution function in the range of large $W$, and the parameter entering the exponent $2 q=\alpha_{\mathrm{p}} / g_{\mathrm{p}}$ is the slope of the power function. Increasing $q$ the relative contribution of large particles increases.

There is a quite extensive near-bottom area where the suspended matter is simultaneously exposed to two kinds of turbulence - the near-bottom and subsurface ones. Fig. 1 shows the component $q_{3}(z)$ (curve 1), caused only by subsurface turbulence effect, and the total parameter $q(z)$ (curve 2) obtained in the Yevpatoria coastal area applying the measurement complex "Donnaya stantsiya" [6]. It can be seen that the near-bottom turbulence effect is significant only at a distance of less than $20 \mathrm{~cm}$ from the bottom, but below $5 \mathrm{~cm}$, it becomes decisive.

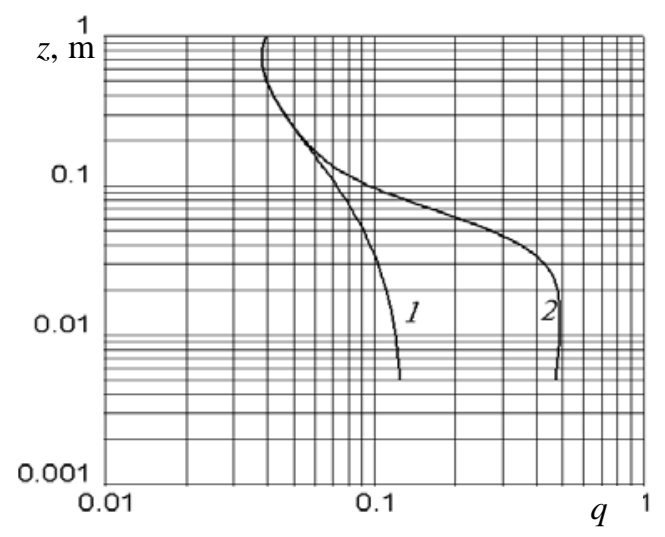

Fig. 1. Change of the distribution $\varphi(W)$ with depth of the parameter $q: 1-q_{3}(z) ; 2$ - total $q(z)$

Directly near the bottom there is a layer several centimeters thick, where the intensity of the near-bottom turbulence depends on the wave phase. Turbulent energy maxima are formed twice during a period. During this time a number of large particles have time to pass into a suspended state and perform a reciprocating movement in the direction of wave propagation. In the phase of turbulent energy minima, hydraulically large particles sink to the bottom, so they can be considered ripple-wake.

In 2010-2012 a series of full-scale experiments was carried on the Bakal Spit applying the measurement complex "Donnaya stantsiya" developed at MHI. Its main feature is the possibility of obtaining three coordinate components of the 
near-bottom flow in the wave and turbulent regions of the spectrum by means of the current velocity vector pulsation meter (CVVPM) [5, 6].

Measurements by the "Donnaya stantsiya" complex fix the anisotropy of wave velocities in the frontal propagation of waves, when in the half-period being directed towards the shore the velocity amplitude is somewhat smaller under a larger pulse width, and the half-period directed from the shore turns out to be narrower under larger amplitude. It turned out to be possible to create a new physical model for the normal-to-coast movement of large sediment particles on the basis of the phenomenon observed and to compare the characteristics of the model transport with the actual events of the Bakal Spit erosion.

The erosion of the narrow part of the Bakal Spit monitored during the expedition in late August - early September 2010. The main body of "Donnaya station" with the

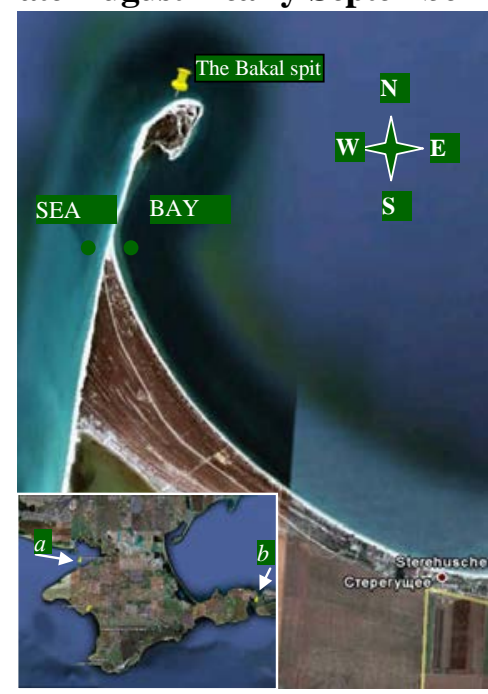
module of dynamic parameter meters and a separate unit for measuring the mean velocity of the bottom current on the basis of the modernized hydrometric current meter (VG-1-120/70) were placed on August 30 from the sea side of the Spit, as shown in Fig. 2. The equipment was installed at a depth of $1.5 \mathrm{~m}$, fluctuations in the flow velocity were measured at a horizon of $0.25 \mathrm{~m}$ from the bottom. The general sequence of events can be traced from the wind velocity and direction variability graphs, as well as from the near-bottom current velocity and direction for 2.5 day period (Fig. 3).

Fig. 2. Experimental sites. In the insert figure: $a$ - the Bakal Spit, $b$ - the Tuzla Spit island

The persistent northeastern wind of $7 \mathrm{~m} / \mathrm{s}$ formed quite intense waves moving along the coastline on the eastern side of the Bakal Spit on August 31. At this time, the main complex of the equipment was rearranged from the sea side to the bay side (Fig. 2). Until the evening of August 31, 14 records of dynamic parameters with 20-25 min duration each were obtained. The block for near-bottom current mean velocity recording was left on the marine side of the spit, and measurements of the coastal currents were not interrupted.

During the night the wind changed its direction to the western one, and the coastal current acquired the northern direction by morning. By this moment the complex of equipment "Donnaya Station" with the module of dynamic parameter meters was placed back to the marine side of the spit. Here for the period from 11:00 to 20:00 on September 1, 17 records of dynamic parameters were obtained. By 15:00 the western wind had already reached $9 \mathrm{~m} / \mathrm{s}$, and after a while the narrow causeway could not withstand the waves. Washing out was discovered during the removal of equipment early in the morning on September 2, when the storm stopped. 


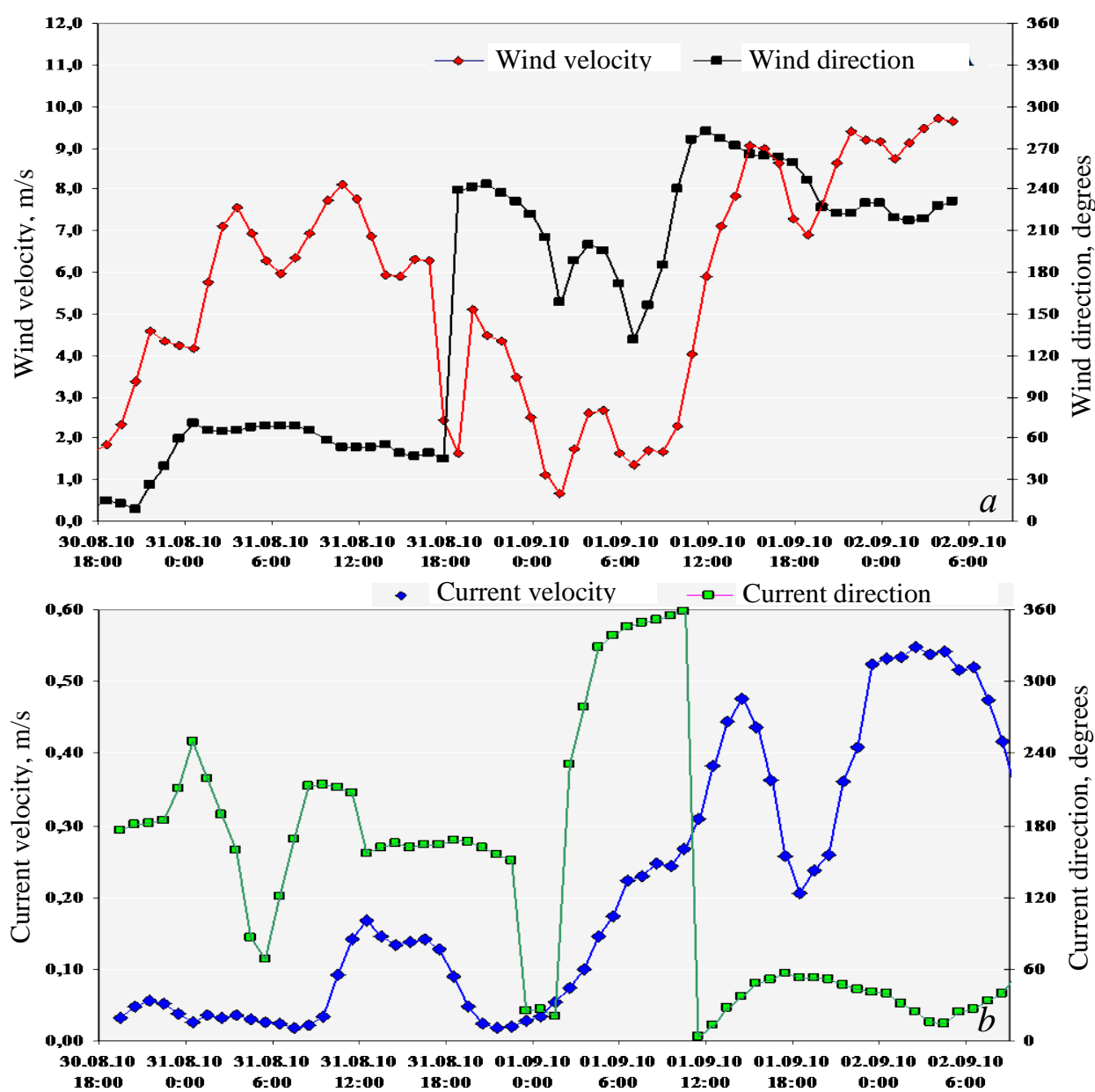

Fig. 3. Summer 2010 changes of: the wind velocity $(H=2 \mathrm{~m})$ and its direction $-a$; the near-bottom current velocity and direction (0.25 m horizon) $-b$

Fig. 4, $a$ shows typical spectra of near-bottom velocities in the gulf to the right side of the Bakal Spit a day before the erosion. Fig. $4, b$ demonstrates the similar spectra obtained already from the Black Sea in about a day, at the time of local erosion of the Spit.

Energy of the alongshore component of the wave velocity is approximately an order larger than the one directed long the normal (Fig. 4, a). Under this direction of waves a gravitational flow is formed in the active bottom layer. It moves the coarse suspension from the shore to the depth. On the Black Sea side under the western wind the normal component of the wave velocity is dominating. It corresponds to the frontal propagation of waves (Fig. 4, $b$ ).

The outlined scenario of the Spit erosion makes it possible to consider the intensive reciprocating normal-to-coast motions of the coarse suspension in the frontal direction of the waves as the main cause of the destruction. 

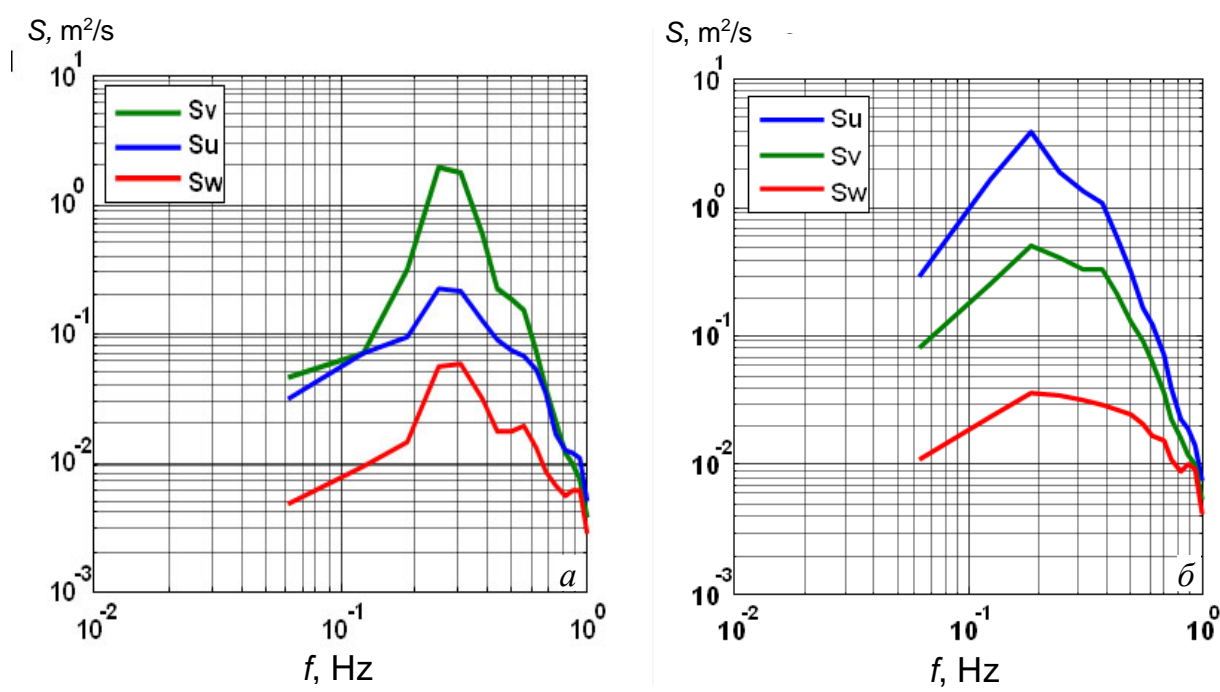

Fig. 4. Spectra of the near-bottom velocity components: $a$ - to the right of the Bakal Spit on Aug 31 2010, alongshore component of the wave velocity is dominating; $b$ - to the left of the Spit on Sept 1 2010, normal-to-coast component of the wave velocity is dominating

Normal-to-coast transfer of the coarse suspension in a surf area has been poorly studied. A possible cause may be technical difficulties arising from in situ studies of fast-changing and irregular processes in this shelf area.

The modeling of such displacements requires a detailed study of the properties of near-bottom turbulence, which actually forms a suspension field at a distance of the first centimeters from the bottom and, thus, is an important component of kinetic models of sediment movement. Near-bottom turbulence as part of the theory of the boundary layer at the solid wall contains a number of theoretical descriptions of the elements that complicate the theory, including the pulsating character of the motion and the multifarious roughness of the bottom. Due to these circumstances, the study of near-bottom turbulence is largely based on empirical data, particularly, on the results of laboratory experiments.

Laboratory model of near-bottom turbulence. Paper [7] represents the results of measurements of pulsations of longitudinal $u$ and vertical $v$ components of the current velocity using a laser Doppler anemometer in a swinging water tunnel with controlled bottom roughness. The summary table shows the main parameters of each of the 19 series of measurements: the mean diameter of the elements of roughness $D$, the amplitude of water velocity oscillations $U_{0}$, the molecular viscosity of water $v$, the friction velocity amplitude $u_{*}=\left(-\overline{u^{\prime} v^{\prime}}\right)^{1 / 2}$, the relation $u_{*} / \overline{u_{*}}$ and the boundary layer thickness $\delta$.

Some general measurement result is that the turbulence intensity is subjected to significant variations with a doubled frequency during the cycle, with the amplitude of the variations decreasing with altitude and the phase shift increasing linearly. At the same time, the height distribution of the mean time intensity of turbulent veloci- 
ty fluctuations qualitatively coincides with that observed under the stable flows. This fact served as the basis for constructing the averaged model of a pulsating nearbottom boundary layer for a coastal zone with a sandy bottom. In this model the phase shifts are not taken into account, and all the relations are derived for the amplitudes and mean values of the considered quantities [8].

On the basis of the laboratory data [7] for the sandy bottom of the tray, an empirical dependence of the thickness of the near-bottom boundary layer $\delta$ on the amplitude of the velocity of water oscillations $U_{0}$ was obtained:

$$
\delta=\theta U_{0} .
$$

where $\theta=38 \cdot 10^{-3} \mathrm{~s}$, if $\delta$ is in meters.

Another important empirical relation can be obtained by constructing a dependence associating the amplitudes of the velocity of water oscillations $U_{0}$ and the friction velocity $u_{*}$. In this case, the linear approximation of laboratory measurements has the following form

$$
U_{0}=30 u_{*} .
$$

Substituting expression (2) in (1), $\delta=30 u_{*} \theta=u_{*} \phi$ and $\phi=30 \theta$ are obtained.

On the basis of the empirical constant $\theta$ introduced in (1), a vortex scale $z_{2}$ can be formed:

$$
z_{2}=\theta u_{*}
$$

The amplitude profile of the flow velocity in that part of it, which is called the logarithmic boundary layer, is represented in the following form

$$
U(z)=A_{2} u_{*} \ln \left(\frac{z}{z_{2}}\right)+B_{2} u_{*},
$$

where $A_{2}=1 / \kappa_{1}=2.172, \kappa_{1}=0.46 ; B_{2}=21.107$.

The model assumes that the near-wall turbulence is generated in a thin layer adjacent to level $z=0$, and then diffuses upward, forming a pulsating near-bottom boundary layer having thickness $\delta$ in accordance with the empirical relationship (1). As a result, an exponential distribution of turbulent energy $E_{T}(z)$ is formed [5], integrating which, an estimate of the turbulent energy in the boundary layer per unit area $\mathrm{E}_{\mathrm{T}}[9,10]$ can be obtained:

$$
\mathrm{E}_{\mathrm{T}}=\int_{0}^{\infty} E_{T}(z) d z=(3 / 2) \rho \sigma^{2} \delta
$$

where $\rho$ is water density; $\sigma$ is the rms deviation of any of the components of the velocity pulsations at the level $z=0$.

In the model it is assumed that the level of this energy is maintained by the loss of momentum in the layer $0 \leq z \leq z_{2}$. The momentum flux $P_{2}$ in the given layer 
in the absence of losses is represented in the form $P_{2}=\rho\left[U\left(z_{2}\right)\right]^{2} z_{2}$ [11]. The half the flow $P_{2}$ is considered to be spent on maintaining the level of turbulence in the entire boundary layer $\mathrm{E}_{\mathrm{T}}$. As a result, taking into account $U\left(z_{2}\right)=B_{2} u_{*}$ the following expression is obtained

$$
\sigma^{2}=\frac{z_{2} B_{2}^{2} u_{*}^{2}}{3 \delta} .
$$

Model calculations are consistent with laboratory measurements of the intensity of turbulent pulsations of the horizontal velocity component for various flow velocity amplitudes [8].

Estimates of the coarse suspension movement under the frontal propagation of waves. Fig. 5 shows the oscillations of the longitudinal component of the

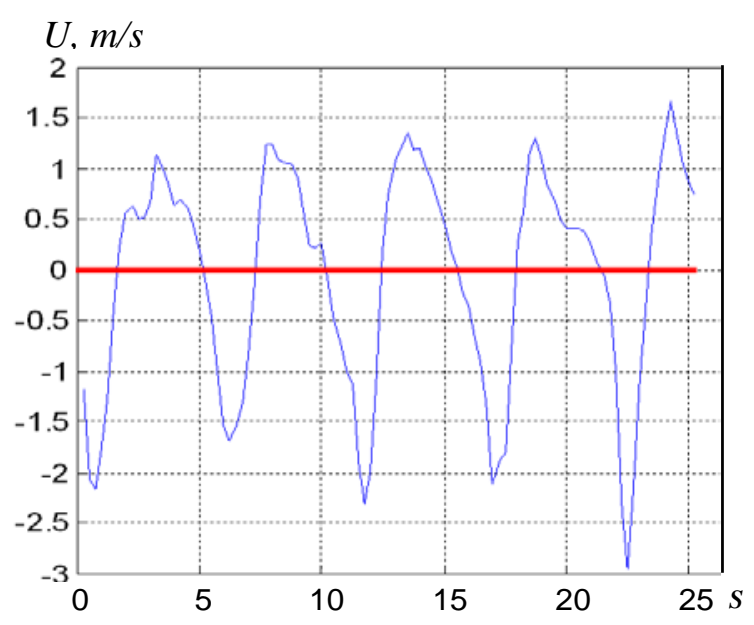

Fig. 5. Anisotropy of the normal-to-coast component of the velocity $U$ at $0.25 \mathrm{~m}$ horizon according to the measurements at the Bakal Spit on Sept 012010 г. at 6pm current velocity under the normal to the coast wave direction. The data were obtained at the Bakal Spit during the aforementioned expedition in late August - early September 2010 under a western wind of $9 \mathrm{~m} / \mathrm{s}$. To construct a graph the data with the initial sampling frequency of $100 \mathrm{~Hz}$ were averaged to a frequency of 4 counts per second. Negative values of the velocity correspond to the direction from the shore.

There is a stable anisotropy of the wave velocities near the bottom, when the directed-to-coast current velocity amplitude is much smaller under a larger pulse width, and the directed-from-coast half-period turns out to be narrower under larger amplitude. It can be expected that in such conditions, the pulsating flows of the coarse near-bottom suspension will also depend on the direction. The short fragment shown in Fig. 5 is typical for the entire series of evening recordings and is optimal for illustration and processing.

According to the processing results the mean positive amplitude is $U_{01}=1.33 \mathrm{~m} / \mathrm{s}$ and the mean negative one $-U_{02}=2.25 \mathrm{~m} / \mathrm{s}$. The relation is $U_{02} / U_{01}=1.71$. Correspondingly, the mean positive half-period was equal to $T_{1}=3.25 \mathrm{~s}$, the mean negative half-period $T_{2}=2.19 \mathrm{~s}$ and the relation $T_{1} / T_{2}=1.49$. The mean period of the oscillations observed was $T=T_{1}+T_{2}=5.43 \mathrm{~s}$. Replacing the real form of positive and negative oscillations with half-wave sinusoids with half-cycles $T_{1}$ and $T_{2}$, it is possible to construct a regular anisotropic sinusoidal 
model for aimed for analyzing the multidirectional flows of the coarse suspension. At the same time it becomes possible to apply the results of laboratory experiments [7], taking into account, in addition to the model from [8], additional phase shifts between the wave oscillations of the flow velocity and the intensity of the generated near-bottom turbulence.

In accordance with the data of [7], the phase lag between the oscillations of the wave velocity with the frequency $\omega$ and the intensity maximum of the turbulent pulsations generated due to the bottom roughness increases linearly with an increase in the normalized distance from the bottom $z / \delta$, so that the corresponding derivative is represented by expression $d(\omega t) / d(z / \delta)=2,27 \mathrm{rad}$.

The vertical velocity $V_{\text {turb }}$ of the maximum shift developed in the layer of turbulent fluctuation roughness turns out to be proportional to the boundary layer thickness $\delta$, and, since the turbulent energy maxima are formed with a double frequency, $V_{\text {turb }}=2 \omega \delta / 2,27=\omega \delta / 1,135$.

According to (1) the velocity $V_{\text {turb }}$ grows proportionally with the wave amplitude $U_{0}$, consequently, поэтому можно считать, the turbulent pulsation maximum at the horizon $\delta$ can be considered to appear with the constant lag $\tau$, independent from the wave amplitude, $\tau=\delta / V_{\text {turb }}$. Taking into account that $\omega=2 \pi / T$ and that $T=4.6 \mathrm{~s}$ in [7], the amplitude-independent lag value $\tau=0,18 T=0.83 \mathrm{~s}$ can be obtained.

The lag in the "filling" of the near-bottom boundary layer of the roughness generated in the high-frequency turbulence layer makes it possible to construct a simplified model of the reciprocal normal-to-coast transfer of the coarse suspension. The model describes the movement of particles that, according to $W_{K}$ (median fall diameter), go up in the boundary layer to the height $\delta$ only at sufficiently high levels of vertical velocity turbulent pulsations and rapidly descend to the bottom during the time $t_{\kappa}=\delta / W_{K}$ when the turbulence intensity decreases. For mineral particles with a diameter of $1 \mathrm{~mm} W$ is $0.1 \mathrm{~m} / \mathrm{s}$ and the deposition time is a fraction of a second [12].

According to (5) the turbulent fluctuation energy in the boundary layer with the thickness $\delta$ is $\mathrm{E}_{\mathrm{T}}=(3 / 2) \rho \sigma^{2} \delta$ and taking into consideration (1) - (3), (6) can be expressed in terms of the amplitude of the wave oscillations $U_{0}$ :

$$
\mathrm{E}_{\mathrm{T}}=0,312 U_{0}^{3} \mathrm{~J} / \mathrm{m}^{2} .
$$

Here and elsewhere $U_{0}(\mathrm{~m} / \mathrm{s})$ shall mean a numerical value of the amplitude. Due to the turbulent fluctuation energy over the sandy bottom, a certain amount of solid particles with the concentration equal to $C$ is held in suspended state [13]. The potential energy of particles $P_{\delta}$ in the boundary layer has the following form

$$
P_{\delta}=\int_{0}^{\delta} C g_{\mathrm{p}} z d z=\frac{1}{2} C g_{\mathrm{p}} \delta^{2},
$$


where $g_{\mathrm{p}}$ is the reduced acceleration of a mineral particle with a density $\rho_{1}=2650 \mathrm{~kg} / \mathrm{m}^{3}$ when falling in still water, $g_{\mathrm{p}}=2\left(\rho_{1}-\rho\right) g /\left(2 \rho_{1}+\rho\right)=$ $=5.133 \mathrm{~m} / \mathrm{s}^{2}, \rho$ is the water density [12].

Since only a part of the turbulence energy is used to maintain the large particles suspended, the relation $P_{\delta}=\mathrm{E}_{\mathrm{T}} / 2$. will be taken for the model assessment. Then $C=44 U_{0} \mathrm{~kg} / \mathrm{m}^{3}$ is obtained for the concentration of the large particles in the boundary layer $C=44 U_{0} \mathrm{~kg} / \mathrm{m}^{3}$, accordingly, the mass of suspended large particles in the boundary layer will be equal to

$$
M=C \delta=1,65 U_{0}^{2} \mathrm{~kg} / \mathrm{m}^{2} .
$$

Flow of the coarse suspension to the shore $\Pi_{1}$ in accordance with the conditions of the model is expressed as follows

$$
\Pi_{1}=\frac{2}{\pi} M_{1} U_{01} \frac{T_{1}-\tau}{T}=1,16 \frac{\mathrm{kg}}{\mathrm{m} \cdot \mathrm{s}} .
$$

Here the multiplier $2 / \pi$ appears as a result of averaging a half-sinusoid with positive amplitude $U_{01}$. The mass $M_{1}$ is found from (9) for the same value of the amplitude. The flow from the shore $\Pi_{2}$ is determined by the following expression

$$
\Pi_{2}=\frac{2}{\pi} M_{2} U_{2 M} \frac{T_{2}-\tau}{T}=2,23 \frac{\mathrm{kg}}{\mathrm{m} \cdot \mathrm{s}} .
$$

Here instead of the negative amplitude $U_{02}=2.25 \mathrm{~m} / \mathrm{s}$ the model value $U_{2 M}=U_{01}\left(T_{1} / T_{2}\right)=1,49 U_{01}=1.99 \mathrm{~m} / \mathrm{s}$ is used, the mass $M_{2}$ is calculated from (9) appearing at the amplitude $U_{2 M}$. The difference $\Pi_{2}-\Pi_{1}=1,07 \mathrm{~kg} /(\mathrm{m} \cdot \mathrm{s})$, that leads to erosion at a speed of 3.8 tons of sand per hour per one meter of the coastline.

For comparison a fragment of the variability of the longitudinal component of the wave velocity at the Bakal Spit similar to Fig. 5 was processed. It was obtained approximately three hours earlier under less development of waves and wind of the same direction. Anisotropy of the wave velocities was also observed here, and for these data the mean positive amplitude was $U_{01}=1.14 \mathrm{~m} / \mathrm{s}$, the mean negative one was $U_{02}=2.12 \mathrm{~m} / \mathrm{s}$. Their relation was $U_{02} / U_{01}=1.85$. Correspondingly, the mean positive half-period was equal to $T_{1}=2.7 \mathrm{~s}$, the mean negative one was equal to $T_{2}=1.75 \mathrm{~s}$. Their relation was $T_{1} / T_{2}=1.54$. The average period of the fluctuations observed was $T=T_{1}+T_{2}=4.45 \mathrm{~s}$. The model amplitude $-U_{2 M}=U_{01}\left(T_{1} / T_{2}\right)=1,54 U_{01}=1.76 \mathrm{~m} / \mathrm{s}$. Further according to (10) the flow to the shore $\Pi_{1}=0,69 \mathrm{~kg} /(\mathrm{m} \cdot \mathrm{s})$, according to (11) the flow from the shore $\Pi_{2}=1,31 \mathrm{~kg} /(\mathrm{m} \cdot \mathrm{s})$. The difference was $\Pi_{2}-\Pi_{1}=0,62 \mathrm{~kg} /(\mathrm{m} \cdot \mathrm{s})$, that leads to erosion at a speed of 2 tons of sand per hour per one meter of the coastline. Thus, with a decrease in the wave period from $5.43 \mathrm{~s}$ to $4.45 \mathrm{~s}$, the flow from the shore decreases almost twofold. 
The scheme of a regular anisotropic sinusoidal model is shown in Fig. 6. The relation $T_{1} / T_{2}$ practically doesn't change,

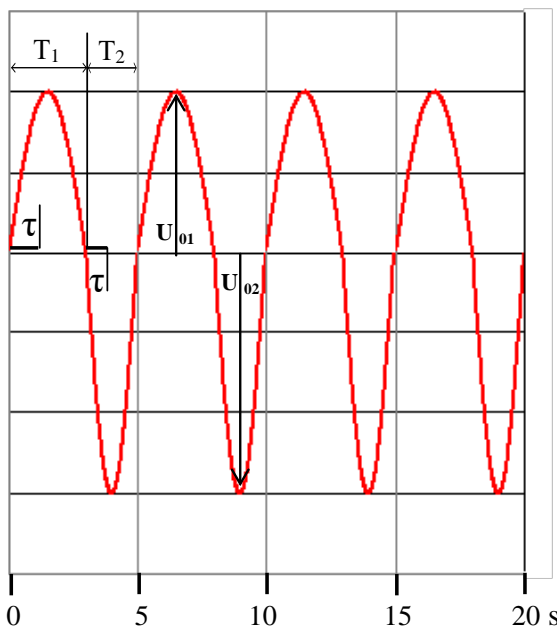

Fig. 6. The normal-to-coast wave velocity component shape for the an anisotropic model so the constant value $T_{1} / T_{2}=1.5$ is applied for the model calculations. At the same time, the ratio of the negative and positive amplitudes of the proposed anisotropic sinusoidal model is also fixed. It allows obtaining the critical value of the wave period at which the flows of the coarse suspension to and from the shore are equal. From the condition $\Pi_{1}=\Pi_{2}$, $T_{\text {кр }}=3,17 \tau=2,6 \mathrm{c}$ is obtained. For the wave periods abrasion changes to accumulation less than the critical.

The results of statistical assessment of the dependence of the period of the spectral maximum frequency $T_{\max }$ on the wind velocity $V$ on the basis of the data array obtained in expeditions to the Bakal Spit (August-September 2010, June 2011 and June 2012) are presented in Fig. 7. The represented linear trend $y=0,561 x$ is calculated taking into account the data for the steady western winds.

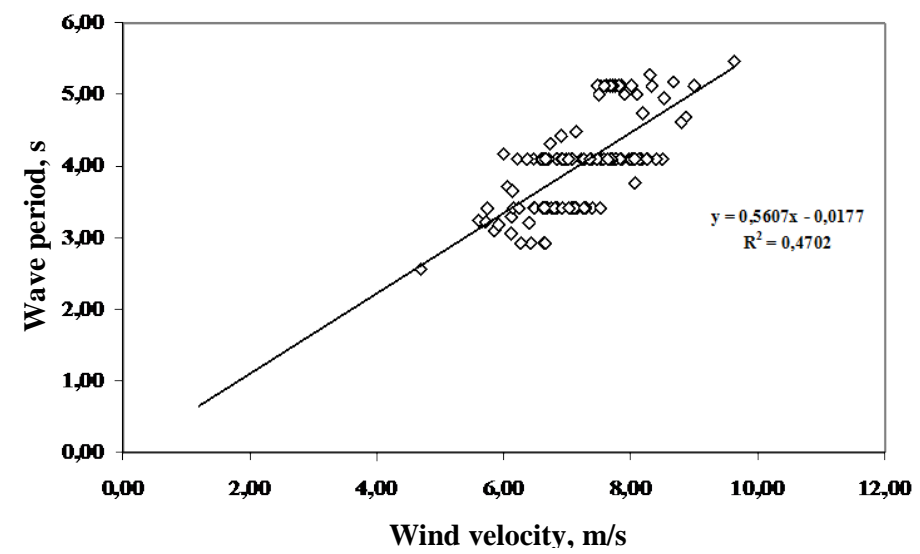

Fig. 7. The results of statistical assessment of the dependence of the period $T_{\max }$ on the wind velocity $V$ on the basis of the data of three expeditions in 2010, 2011 and 2012

A low level of the determination coefficient $R^{2}$ can be caused by the fact that the wind velocity is measured on the shore, while the characteristics of the wind field on the acceleration line determining the conditions for the formation of the wave spectrum in the open sea may not coincide with those measured at the observation point.

Applying the dependence $V=0,561 T_{\max }$ for the critical period $2.6 \mathrm{~s}$ the neutral wind force $4.7 \mathrm{~m} / \mathrm{s}$ is obtained. Under such a wind, there is no total normal-to-coast transfer of the coarse suspension. 
Discussion and conclusion. The represented model of the normal-to-coast transfer of the coarse suspension makes it possible the rapid erosion of the Bakal Spit to be explicable in accordance with the aforementioned scenario. Fig. 8 shows the time of the Bakal Spit destruction in late August - early September 2010 including the formation of an enormous large washing out further having become gradually larger.

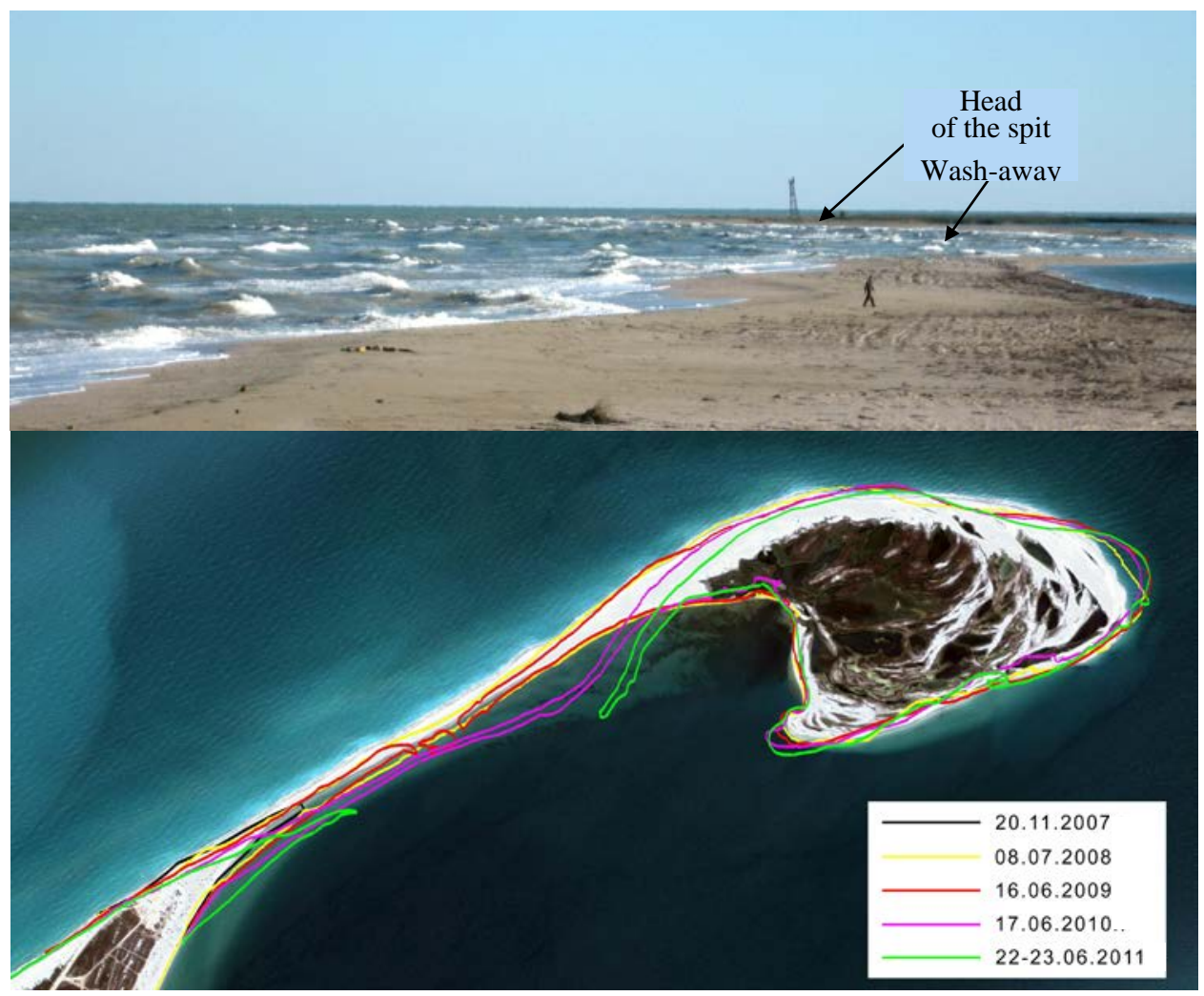

Fig. 8. The Bakal Spit destruction in late August - early September 2010 including the formation of an enormous large washing out further having become gradually larger.

In the situation under discussion, the final separation of the distal part with the formation of a washing out with width exceeding $600 \mathrm{~m}$ and the maximum depth reaching $3 \mathrm{~m}$ by the summer of 2011 .

More detailed chronology of the events is presented in [14, 15]. Separation connection processes and of the distal part with the spit body had been repeatedly observed earlier, in 2007-2009. After the next separation, the isthmus was formed again; however, its width decreased each time. By the summer of 2010, the isthmus width was only 10-12 m, and it took the S-shape itself.

It can be calculated that to eliminate such a narrow isthmus, it was necessary to move $20 \mathrm{~m}^{3}$ of sand per one meter of the shoreline to the depth, totally a little bit more than 50 tons. Under the conditions shown in Fig. 5, when the flow of the coarse sandy suspension is modeled as 3.8 tons per hour per one meter of shoreline, this process can take about 13 hours; and under conditions that existed 3 hours ear- 
lier - about 25 hours. The moment of the washing out occurrence was not fixed accurately, but according to Fig. 3 the duration of erosion (from 2pm to 6am) did not exceed 16 hours.

We can assume that the model calculations of normal-to-coast transfer velocity of the coarse suspension in the case at hand give results comparable to the actual course of events. The temporary sea level rise, according to the "Donnaya Stantsiya” pressure channel data, was $25-30 \mathrm{~cm}$ under the western wind at the time of erosion.

The outlined physical model of the reciprocal normal-to-coast transfers of the coarse suspension under the frontal direction of the waves is of a considerably preliminary, pilot character, since it is based on measurements carried out in a single area. It is necessary to perform additional studies in various locations along the coast applying the existing measuring complex "Donnaya Stantsiya” to verify the universality degree of the main parameters of the model.

Meanwhile, even in such a pilot version, the model can be applied to the analysis of the analogic situations. There is a certain similarity of the dramatic events on the Bakal Spit and Tuzla Spit in the Kerch Strait. As is known, before 1925 it existed as a single whole with the Taman Peninsula. In November 1925 during a violent storm of the south-western rumba, a breakthrough occurred in the root of the spit. A washing out was formed with a width of up to $300 \mathrm{~m}$, which had already increased to $960 \mathrm{~m}$ by 1926. It erosion continued until 2003, before the construction of the protective dam on the mainland part of the spit [14].

According to measuring complex "Donnaya Stantsiya", the wave spectra show that under northern winds of different intensity, the main wave period in the Taman Bay usually does not exceed $T=2 \mathrm{~s}$ that, according to the model developed, corresponds to the accumulation regime. Waves from the Black Sea side can develop up to large periods corresponding, according to the model, to the erosion situation. Thus, in the modern geological conditions, with accumulation in the gulf and erosion from the sea, the Tuzla Island should generally move in the northern direction. According to indirect estimates, based on data on the displacement of the residual underwater shaft in 1950-2000, the speed of such displacement is $1.5 \mathrm{~m}$ per year.

This phenomenon is of great importance in connection with the construction of a bridge across the Kerch Strait on the basis the Tuzla Island. In accordance with the model above, in the next 50 years the Tuzla Island can move to the north by $75 \mathrm{~m}$, which will change the location of the bridge supports relative to the shoreline. It is advisable to carry out special in situ research using measuring complex "Donnaya Stantsiya" to clarify the specific characteristics of the spit "washing out" and the development of appropriate recommendations.

Acknowledgements. The work was carried out with the framework of the State Order No. 0827-2014-0010 Complex Interdisciplinary Research of the Oceanological Processes Determine the Functioning and Evolution of the Ecosystems of the Black and Azov Seas, based on Modern Methods for Marine Environment State and Grid Technologies (Fundamental oceanology). 


\section{REFERENCES}

1. Ivanov, V.A. and Mikhinov, A.E., 1991. Prognoz Dinamiki Nanosov v Pribrezhnoi Zone (Prakticheskie Rekomendacii I Parametry Raschetov) [Forecast of the Dynamic of Sediment Motion in the Coastal Zone (Practical Recommendation and Calculation Parameters)]. Sevastopol: MHI, 52 p. (in Russian).

2. Lee, T.H. and Hanes, D.M., 1996. Comparison of Field Observations of the Vertical Distribution of Suspended Sand and its Prediction by Models. J. Geophys., [e-journal] 101(C2), pp. 3561-3572. doi:10.1029/95JC03283

3. Murray, S.P., 1970. Settling Velocities and Vertical Diffusion of Particles in Turbulent Water. J. Geophys., [e-journal] 75(9), pp. 1647-1654. doi:10.1029/JC075i009p01647

4. Antsyferov, S.M., Belberov, Z.K., Massel, S.R. and Popov, V.G., 1990. Dynamical Processes in Coastal Regions: Results of the Kamchiya International Project. Sofia: Pub. House of the Bulgarian Academy of Sciences, $190 \mathrm{p}$.

5. Ivanov, V.A., Dykman, V.Z., Efremov, O.I., Zima, V.V. and Bol'shakov, A.N., 2006. Sovremennye Metody I Sredstva Kontrolja Morskoj Sredy [Modern Methods and Means of Control of the Marine Environment]. Sevastopol: ECOSI-Gidrofizika, 110 p. (in Russian).

6. Dykman, V.Z., Efremov, O.I. and Man'kovskaya, E.V., 2011. Field Studies of the Motion of Sediments in the Coastal Zone of the Sea. Physical Oceanography, [e-journal] 20(379), pp. 122-135. doi:10.1007/s11110-011-9093-7

7. Sleath, J., 1987. Turbulent Oscillatory Flow over Rough Beds. J. Fluid Mech., [e-journal] 182, pp. 369-409. doi:10.1017/S0022112087002374

8. Dykman, V.Z., Efremov, O.I and Ivanov, V.A., 2010. A Model of the Bottom Turbulent Layer in the Shallow-Water Region. Physical Oceanography, [e-journal] 20(2), pp. 122-135. doi:10.1007/s11110-010-9072-4

9. Monin, A.S. and Yaglom, A.M., 1968. Statistical Hydrodynamics. Washington, D.C.: United States. Department of Commerce, Clearinghouse for Federal Scientific and Technical Information, $720 \mathrm{p}$.

10. Phillips, O.M., 1977. The Dynamics of the Upper Ocean. Cambridge: Cambridge University Press, $336 \mathrm{p}$.

11. Le Méhauté, B., 1974. An Introduction to Hydrodynamics and Water Waves. New York: Springer Science+Business Media, LLC, 323p. doi:10.1007/978-3-642-85567-2

12. Efremov, O.I., 2013. Gidravlicheskaja Krupnost' Razlichnyh Komponent Vzvesi v Morskoi Vode [Settling Velocity Different Components of Suspended Sediment in Salt Water]. Sistemy Kontrolja Okruzhajushhej Sredy, (19), pp. 148-155 (in Russian).

13. Ivanov, V.A., Dykman, V.Z. and Efremov, O.I., 2009. Kinetika Dvizheniya Vzvesey v Beregovoy Zone [Kinetics of the Suspended Matter Motion in the Coastal Zone]. In: Akivis, T.M. and Pyhov, N.V. eds., 2009. Litodinamika Donnoi Kontaktnoi Zony Okeana: Materialy Mezhdunarodnoi konferencii, posvjachshennoi 100-letiyu so dnja rozhdeniya V.V. Longinova, 14-17 sentyabrya 2009, Moskva [Lithodynamics of the Bottom Ocean Contact Zone: Proc. International Conference dedicated to the Centenary of the Birth of V. Longinov, 14-17 September 2009, Moscow]. Moscow: GEOS, 167 p. (in Russian).

14. Gorjachkin, Ju.N. and Dolotov, V.V., 2011. Izmenenija Beregovoj Linii Akkumuljativnyh Beregov Zapadnogo Kryma [The Changes of Accumulative Coastline of the Western Crimea]. In: MHI NASU, 2011. Ekologicheskaya Bezopasnost' Pribrezhnoy i Shel'fovoy Zon i Kompleksnoe Ispol'zovanie Resursov Shel'fa [Ecological Safety of Coastal and Shelf Zones and Comprehensive Use of Shelf Resources]. Sevastopol: MHI NASU. Vol. 1, No. 25, pp. 8-18 (in Russian).

15. Ivanov, V.A., Gorjachkin, Ju.N., Udovik, V.F., Haritonova, L.V. and Shutov, S.A., 2012. Sovremennoe Sostojanie i Jevoljucija Bakal'skoj Kosy [Modern Conditions and Evolution of the Coastline in the Bakal Spit Area (the North-Western Crimea)]. In: MSI NANU, 2012. Ekologicheskaya Bezopasnost' Pribrezhnoy i Shel'fovoy Zon i Kompleksnoe Ispol'zovanie Resursov Shel'fa [Ecological Safety of Coastal and Shelf Zones and Comprehensive Use of Shelf Resources]. Sevastopol: MHI NASU. Vol. 1, No. 26, pp. 8-15 (in Russian). 